\title{
Evaluation of Speech Intelligibility of a Cleft Palate Patient with Speech Prosthesis before and after Palatographical Analysis and Prosthesis Modification
}

\author{
Nikhil S. Rajan1, Lovely Muthiah2², Jovita D'souza3, Biji Thomas George ${ }^{4}$ \\ ${ }^{1}$ Department of Prosthodontics, Sri Sankara Dental College, Trivandrum, India \\ ${ }^{2}$ Department of Prosthodontics, Ras Al Khaimah College of Dental Sciences, Ras Al Khaimah, UAE \\ ${ }^{3}$ Department of Periodontics, Ras Al Khaimah College of Dental Sciences, Ras Al Khaimah, UAE \\ ${ }^{4}$ Department of Surgery, S.K Hospital, Trivandrum, India \\ Email: drnikhils@gmail.com, *mlovely@gmail.com,dr.jovita@gmail.com,drbiji@gmail.com
}

How to cite this paper: S. Rajan, N., Muthiah, L., D'souza, J. and George, B.T. (2017) Evaluation of Speech Intelligibility of a Cleft Palate Patient with Speech Prosthesis before and After Palatographical Analysis and Prosthesis Modification. Journal of Biosciences and Medicines, 5, 60-69. https://doi.org/10.4236/jbm.2017.56006

Received: April 21, 2017

Accepted: June 24, 2017

Published: June 27, 2017

Copyright (๑) 2017 by authors and Scientific Research Publishing Inc. This work is licensed under the Creative Commons Attribution International License (CC BY 4.0).

http://creativecommons.org/licenses/by/4.0/

\begin{abstract}
The aim of the study was to evaluate the alterations in speech intelligibility in a cleft palate patient, before and after extending and modifying the palatal contour of the existing prosthesis using a correctable wax recording. An eight-year-old girl studying in second grade with a velopharyngeal defect using an obturator reported to the outpatient clinic complaining of lack in clarity of speech. The existing prosthesis was lacking a speech bulb hence it was decided to add the speech bulb to the existing prosthesis and evaluate the speech. Even after the use of speech bulb it was observed that she was unable to pronounce the vowels and words like shoe, vision, cheer, etc. clearly. Hence, a palatography was done using a correctable wax technique and the existing prosthesis was altered accordingly. Great improvement in speech, mastication, and velopharyngeal function was achieved after the palatography alteration of the existing prosthesis.
\end{abstract}

\section{Keywords}

Speech Prosthesis, Speech Intelligibility, Palatography, Phonetics, Cleft Palate

\section{Introduction}

Children with cleft palate often present with hypernasal speech, most commonly due to a structural deficiency of the velum. Some reports indicate that $20 \%$ to $43 \%$ of these children will still have velopharyngeal insufficiency following surgical palatal repair, and as a result may continue to sound hypernasal [1]. Velo- 
pharyngeal dysfunction may be treated surgically, prosthetically, by speech therapy, or a combination approach. The speech prosthesis may be the best choice in several situations where surgery is not the treatment of choice due to systemic, anatomic, or functional limitations or if the patient is not willing to undergo any surgical procedure [2]. The relationship between speech intelligibility and a speech prosthesis in patients with cleft palate is still a matter of concern, and there lies a continuous pursue to understanding more clearly the relationship between speech prosthesis and speech intelligibility and also improvising on the various methods and techniques to analyze, assess and manage patients with cleft palate defects.

Primary objectives for prosthodontic therapy include restoration of mastication, deglutition, and speech that is clinically and functionally acceptable. The definitive prosthesis generally used for this purpose is an obturator. An obturator should be a single piece either closed or open type. Accumulations of nasal secretions causing unpleasant odour and difficulty in polishing the internal surfaces are some of the disadvantages of an open type obturator [3]. Hence, a closed light weight hollow bulb obturator is preferred as it is easier to maintain [4]. Although, obturators aid in better mastication and deglutition, speech defects still persist to a large extent. Hence, the routine practice has been to put the patient on an intensive speech therapy. Patients with cleft palate have abnormalities in nasal resonance due to a velopharyngeal dysfunction. Speech bulbs aid as a stimulus intended to increase movements of the pharyngeal walls and palate, and hence, help to improve velopharyngeal closure [5]. Apart from this, existing articulation errors also result in reduced speech intelligibility [6]. Correlation between speech intelligibility and speech prosthesis is crucial and understanding this dimension thoroughly will definitely aid in enhancing speech intelligibility through prosthesis. Articulatory records between the tongue and the palate during various speech sounds can be recorded with palatography techniques. Commonly, marker paint is used on the tongue or palate to evaluate the articulation and are called linguograms or palatograms, respectively. In this case report, palatography was done using the correctable wax technique and the existing prosthesis was altered accordingly. The objective of this case report was to evaluate the alterations in speech intelligibility after extending the existing prosthesis to cover the soft tissue defect and modifying the palatal contour using the aforementioned technique.

\section{Case Report}

An 8-year old female patient reported to the department of Prosthodontics at Sree Mookambika Institute Of Dental Science, Kulasekaram, Tamilnadu. She had an existing prosthesis for correction of the defect, but complained that she was unable to speak clearly with the existing prosthesis (Table 1).

On intra oral examination a group II cleft palatal defect according to Veau's Classification was present, which involved the hard palate and extended to the soft palate (velum) revealing a velopharyngeal defect as well. (Figure 1(a)) The 
Table 1. Socio-demographic and clinical characteristics of child.

\begin{tabular}{c}
\hline Child's socio-demogr \\
Age \\
Gender \\
Education \\
Parent's socio-economic status \\
\hline Type of defect \\
\hline Type of existing prosthesis \\
\hline No o \\
\hline
\end{tabular}

(a)

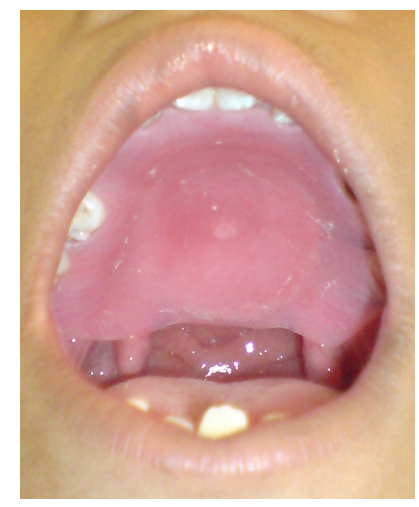

(b)

Figure 1. (a) Hard palate and Velopharyngeal defect; (b) patient's existing prosthesis.

existing prosthesis did not cover the defect that involved the soft tissue part (velum). (Figure 1(b))

It was observed that, during speech the patient had high nasality and unintelligible speech. The initial treatment plan was to add a hollow speech bulb to the existing prosthesis.

The patient's speech was evaluated in three clinical intervals. In the first visit, speech evaluation was done with the existing prosthesis. In the second visit, the analysis was done after adding a speech bulb to the existing prosthesis and in the third visit analysis was done after modifying the corrected prosthesis using the Korrecta wax palatography technique.

The speech was evaluated for nasality with a Nasometer. Praat software was used to evaluate the formants. Speech intelligibility was done using three vowels $|\mathrm{a}|,|\mathrm{e}|,|\mathrm{u}|$, and was assessed using the listener scale. The patient's parent's consent was taken for the publication of this case report.

\section{Clinical Procedure}

A primary impression was recorded using Putty Impression material (Elite Zhermeck) after blocking the undercut intra orally by placing gauze. The cast was poured using Dental stone (Kalabhai). The existing prosthesis was tried on 
to the cast and the extension to the velopharyngeal defect was assessed. A 21-gauge stainless steel wire was incorporated onto the posterior extent of the prosthesis, which would aid in support of the impression material during recording the defect extending into the velum (Figure 2).

A pick up impression was done in putty. Impression Compound and green stick compound in the ratio of 7:1 was placed in a hot water bath and placed over the wired extension of the existing prosthesis. The velopharyngeal defect was recorded with the existing prosthesis along with the extension, which worked as the secondary tray (Figure 3 ).

During the molding of the velopharyngeal area the patient was asked to move her head forward by touching her chin on her chest and backward, and sideways touching her chin on her shoulders. This procedure was repeated until her nasality was considerably decreased. The patient was also asked to speak during the impression procedure.

The cast was poured with die stone, wax up was done and a hollow bulb obturator was constructed using salt method. Base of the obturator bulb was constructed using heat cure acrylic (Acrlyn-H, India) and the roof of the obturator was constructed using salt method using self-cure acrylic (Acralyn-H, India) (Figure 4).

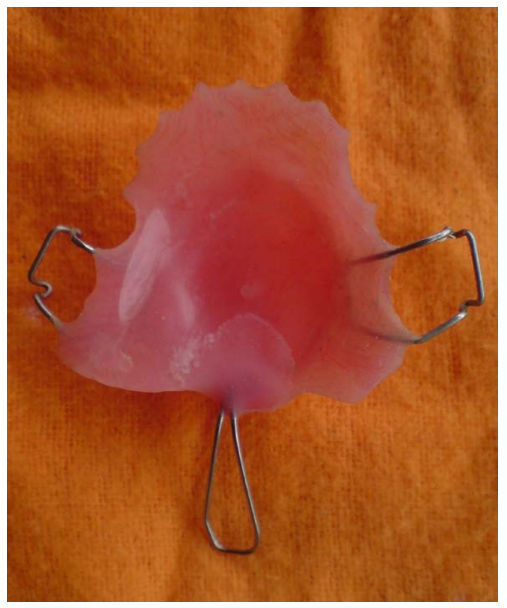

Figure 2. A 21-gauge stainless steel wire incorporated onto the posterior extent of the prosthesis.

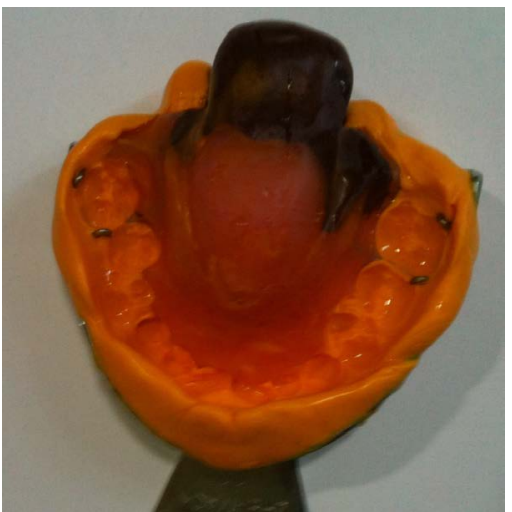

Figure 3. Velopharyngeal defect recorded. 


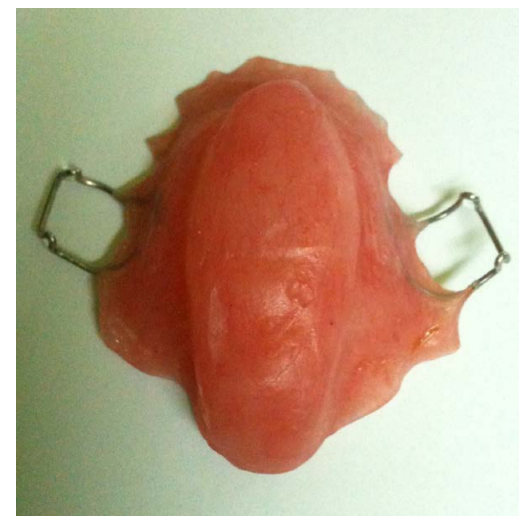

Figure 4. Obturator bulb.

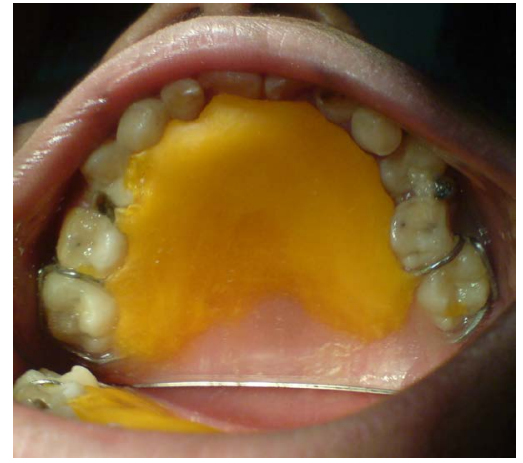

Figure 5. Intra oral correcta wax impression.

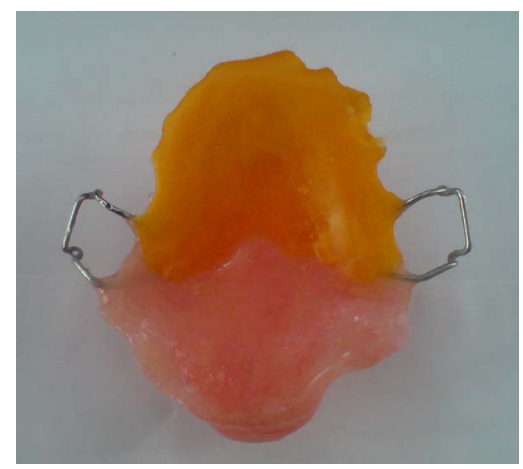

Figure 6. Final corrective impression.

The prosthesis was then tried in the patient. Speech was assessed using the intelligibility test by listener scale analysis. The patient showed decreased nasality and speech was more intelligible, but clarity of speech was still lacking. Hence, the palatal aspect of the prosthesis was coated with Korrecta wax and left to mould after asking the patient to repeat vowels and many words like shoe, cheer, fishing etc. The final corrective impression was made with Korrecta No 10 wax (factor II company). It was observed that the palatal contour took a different shape when she was able to speak more clearly (Figure 5, Figure 6).

This contour was copied and converted to acrylic resin and the prosthesis was polished and finished and speech evaluation with Nasometer and an intelligibility test using the listeners scale was assessed again. All the evaluation using na- 
someter and and Praat software analysis were done in a sound proof room of 20 $\mathrm{db}$ (Courtsey NISH Trivandrum). Speech intelligibility was tested using three vowels $|\mathrm{a}|,|\mathrm{e}|,|\mathrm{u}|$, and was assessed using the listener scale.

A remarkable improvement in all the parameters was observed.

\section{Results}

It was observed that the speech clarity for the vowels improved significantly after modification of the prosthesis. The values are depicted in Tables 2-4. There was an improvement of nasalance for the vowels after the modification of the prosthesis. The average (SD) percent scores for the 3 groups namely, existing prosthesis, prosthesis after extension and speech bulb, and after modification of the prosthesis with palatography technique for vowel |a| were $62.74 \%$ (1.55\%), $56.64 \%(2.35 \%)$ and $25.32 \%(2.97 \%)$ respectively, for vowel $|\mathrm{e}|$ were $61.40 \%$ (1.03\%), 54.80\% (0.92\%) and $17.34 \%(2.97 \%)$ respectively, and for vowel $|\mathrm{u}|$ were $52.93 \%$ (1.31\%), $44.4 \%(2.78 \%)$ and $26.33 \%$ (2.60\%) respectively (Table 5).

Table 2. Digital acoustic analysis using praat formants values for vowel |a|.

\begin{tabular}{cccc}
\hline Formants & Before prosthesis & After prosthesis & After modified prosthesis \\
\hline f0 & 367.49 & 354.28 & 355.3 \\
f1 & 1124 & 1043.57 & 1268.08 \\
f2 & 1878.26 & 1785.19 & 1657.67 \\
f3 & 2670.95 & 2442.34 & 2186.18 \\
f4 & 3474.88 & 4032.67 & 3696.88 \\
f5 & 4980.91 & 4730.52 & 4828.18 \\
\hline
\end{tabular}

Table 3. Digital acoustic analysis using praat formants values for vowel |e|.

\begin{tabular}{cccc}
\hline Formants & Before prosthesis & After prosthesis & After modified prosthesis \\
\hline f0 & 403.22 & 359.18 & 373.45 \\
f1 & 726.32 & 544.83 & 548.4 \\
f2 & 2534.34 & 2004.88 & 1931.01 \\
f3 & 2904.03 & 2927.91 & 2962.75 \\
f4 & 4633.07 & 3631.71 & 3931.38 \\
f5 & undefined & 4275.56 & 4847.11 \\
\hline
\end{tabular}

Table 4. Digital acoustic analysis using praat formants values for vowel $|\mathrm{u}|$.

\begin{tabular}{cccc}
\hline Formants & Before prosthesis & After prosthesis & After modified prosthesis \\
\hline f0 & 392.45 & 396.93 & 355.48 \\
f1 & 627 & 522.61 & 703.13 \\
f2 & 1071.9 & 1238.06 & 1137.12 \\
f3 & 3071.48 & 2673.59 & 1951.91 \\
f4 & 4753.38 & 4416.8 & 3826.04 \\
f5 & 4964.27 & 4952.33 & 4798.35 \\
\hline
\end{tabular}


Table 5. Assessment of nasalance for vowels $|\mathrm{a}|,|\mathrm{e}|,|\mathrm{u}| \mathrm{using}$ nasometer.

\begin{tabular}{cccc}
\hline Vowel & $\begin{array}{c}\text { Before prosthesis } \\
\text { Average\% (SD\%) }\end{array}$ & $\begin{array}{c}\text { After prosthesis } \\
\text { Average\% (SD\%) }\end{array}$ & $\begin{array}{c}\text { After modification of } \\
\text { prosthesis Average\% (SD\%) }\end{array}$ \\
\hline a $\mid$ & $62.74 \%(1.55 \%)$ & $56.64 \%(2.35 \%)$ & $25.32 \%(2.97 \%)$ \\
$|\mathrm{e}|$ & $61.40 \%(1.03 \%)$ & $54.80 \%(0.92 \%)$ & $17.34 \%(2.97 \%)$ \\
$|\mathrm{u}|$ & $52.93 \%(1.31 \%)$ & $44.4 \%(2.78 \%)$ & $26.33 \%(2.60 \%)$ \\
\hline
\end{tabular}

\section{Discussion}

Failure of a primary palatoplasty to achieve a desirable functional velopharyngeal port can result in an array of speech problems, including hypernasality, inappropriate nasal air emission, often with development of compensatory articulation patterns in an attempt to produce oral pressure consonants. The extension of the defect beyond the velopharyngeal port results in hypernasality and reduction in speech intelligibility [7]. Yoshida, et al. [8] (2000), pointed out that hypernasality could be either mild or severe and it could generate discrete distortion or a drastic reduction in speech intelligibility respectively, thereby having a direct effect on an individual's communication and social interactions. Data shows that perceptual ratings of resonance which are indicative of increased hypernasality were associated with poorer intelligibility [2].

The literature reveals that as many as $25 \%$ to $50 \%$ of primary surgical closures of the hard and soft palate fail to adequately restore velopharyngeal function and consequently require one or more additional surgical procedures [9] [10] [11] or even require prosthetic treatment [12] [13] to correct the problem. Many reports regarding prosthetic treatment of maxillectomized patients have shown a reduction in hypernasality and a significant increase in the percentage of correctly identified words [1] [14] [15].

Fabricating a hollow obturator bulb is the most common treatment for velopharyngeal defects [16]. Of the different types of obturators, closed obturators have been commonly used [17]. There are several important patient background characteristics and factors, which have to be considered when looking at either clinical speech measurements or patient perceptions to obturator function. It is observed that patients who have undergone resection of maxilla and have dry mouths due to a history of radiotherapy or patients with reduced saliva and/or presence of thicker saliva experience impaired stability and retention of the prosthesis, with difficulties in sound articulation, associated with poorer intelligibility and impaired mastication and deglutition [18] [19]. Obturators are known to function better during communication and swallowing in patients with smaller defects of the hard palate [20]. In individuals with complete unilateral hard and soft palatal defects, Sullivan et al. [21] found a mean intelligibility score of $46.5 \%$ in patients without prosthesis and $79.7 \%$ with prosthesis. In our study, we demonstrated improvements in speech intelligibility in the patient with the use of prosthesis, which is in agreement with results reported in the literature [1] [15] [18] [21] [22]. However, there was a further improvement in 
clarity after modification of the existing prosthesis using the correcta wax palatography technique.

Static palatography was the first concept to study consonants articulations during speech production [23]. The method consists of analyzing the contact area where the tongue touches the palate during the articulation. In order to visualize this contact area, before the consonant production, a paste made half of charcoal and half of olive oil is painted over the tongue. After the consonant production, the articulatory contact leaves a dark print onto the palate, which is analyzed to characterize the articulation. Palatography is said to be direct if the tongue touches the real palate. In this case, the tongue print is observed using a mirror. Palatography is said to be indirect, if an artificial palate is used.

Direct and indirect static palatography has been used in many studies for more than a century. But in the sixties, Electropalatography (EPG) came in and permitted the study of dynamic contacts of tongue to plate [24] [25]. Electropalatography permits contact analysis over time, but it also has limitations. Only points on the palate where electrodes are located are considered and moreover, the artificial palate can disturb the speaker. The EPG plates that are available currently are expensive. Therefore, conducting studies with larger number of speakers becomes practically difficult.

Information about the shape of the palate is quite important in order to understand specificities of certain articulatory behavior patterns as previous studies have pointed out [5]. 2D image analysis have intrinsic limitations since the palate is not flat, and therefore simulating the shape of the palate as much as practically possible is a crucial step. In order to permit palate classification we propose extraction of the $3 \mathrm{D}$ shape to make palate comparison possible. Thus, in this case report we wanted to assess speech intelligibility in cleft palate patients using speech bulb and after altering the palatal contours of the existing prosthesis with palatography using Korrecta wax technique. It was observed that there was an improvement in speech clarity with the existing prosthesis, which was further enhanced with significant improvements by modifying the existing prosthesis using the corrective wax palatography technique. The alteration in the contour and the shape of the palate significantly enhanced the speech intelligibility. Mere placements of obturators in these patients definately help in improving functionality, but slight alterations in thickness and contour and extent of these prosthesis have a tremendous impact on the speech clarity and intelligibility. Understanding this dimension thoroughly will definitely aid in enhancing speech intelligibility through prosthesis.

The encouraging observations and results of this study provides us with a basis to carry out further research in this regard with the ultimate aim to provide near normal speech through prosthetic management.

\section{Conclusion}

To conclude, any defect of the maxilla can be corrected using surgical intervention or by prosthetic management but the ultimate aim to provide with a near 
normal speech lies in the hand of the maxillofacial prosthodontist, who should diagnose the defect and provide a better prosthetic rehabilitation. Modifying the prosthesis using palatography helps the patient to improve intelligibility in speech in very short span of time.

\section{References}

[1] Kummer, A.W., Clark, S.L., Redle, E.E., Thomsen, L.L. and Billmire, D.A. (2012) Current Practice in Assessing and Reporting Speech Outcomes of Cleft Palate and Velopharyngeal Surgery: A Survey of Cleft Palate/Craniofacial Professionals. The Cleft Palate-Craniofacial Journal, 49, 146-152. https://doi.org/10.1597/10-285

[2] Bohle, G., Rieger, J.M., Huryn, J., Verbel, D., Hwang, F. and Zlotolow, L.I. (2005) Efficacy of Speech Aid Prostheses for Acquired Defects of the Soft Palate and Velopharyngeal Inadequacy-Clinical Assessments and Cephalometric Analysis: A Memorial Sloan-Kettering Study. Head \& Neck, 27, 195-207. https://doi.org/10.1002/hed.10360

[3] Beumer, J., Curtis, T.A. and Firtell, D.N. (1979) Maxillofacial Rehabilitation. Prosthodontic and Surgical Considerations. The C.V. Mosby Co., St Louis, Toronto, London.

[4] Shimodaira, K., Yoshida, H., Yusa, H. and Kanazawa, T. (1998) Palatal Augmentation Prosthesis with Alternative Palatal Vaults for Speech and Swallowing: A Clinical Report. Journal of Prosthetic Dentistry, 80, 1. https://doi.org/10.1016/S0022-3913(98)70082-4

[5] Tachimura, T.T., Nohara, K.N., Fujita, Y. and Wada, T. (2002) Change in Levator Veli Palatine Muscle Activity for Patients with Cleft Palate in Association with Placement of a Speech-Aid Prosthesis. The Cleft Palate-Craniofacial Journal, 39, 503-508. https://doi.org/10.1597/1545-1569(2002)039<0503:CILVPM>2.0.CO;2

[6] Bzoch, K.R. (2004) Introduction to the Study of Communicative Disorders in Cleft Palate and Related Craniofacial Anomalies. In: Bzoch, K.R., Ed., Communicative Disorders Related to Cleft Lip and Palate, 5th Edition, PRO-ED, Austin, Texas, 3-65.

[7] McWilliams, B.J. (1966) Speech and Language Problems in Children with Cleft Palate. Journal of the American Medical Women's Association, 21, 1005-1015.

[8] Yoshida, H., Furuya, Y., Shimodaira, K., Kanazawa, T., Kataoka, R. and Takahashi, K. (2000) Spectral Characteristics of Hypernasality in Maxillectomy Patients. Journal of Oral Rehabilitation, 27, 723-730. https://doi.org/10.1046/j.1365-2842.2000.00537.x

[9] McWilliams, B.J., Morris, H.L. and Shelton, R.L. (1990) Cleft Palate Speech. 2nd Edition, BC Decker, Philadelphia.

[10] Hardin-Jones, M., Brown, C.K., Van Demark, D.R. and Morris, H.L. (1993) LongTerm Speech Results of Cleft Palate Patients with Primary Palatoplasty. The Cleft Palate-Craniofacial Journal, 30, 55-63. https://doi.org/10.1597/1545-1569(1993)030<0055:LTSROC>2.3.CO;2

[11] Park, S., Saso, Y., Ito, O., Tokioka, T., Kato, K. and Gitano, I. (2000) The Outcome of Long-Term Follow-Up after Palatoplasty. Plastic and Reconstructive Surgery, 105, 12-17. https://doi.org/10.1097/00006534-200001000-00002

[12] Reisberg, D.J. (2000) Dental and Prosthodontic Care for Patients with Cleft or Craniofacial Conditions. The Cleft Palate-Craniofacial Journal, 37, 534-537. https://doi.org/10.1597/1545-1569(2000)037<0534:DAPCFP>2.0.CO;2

[13] Sun, J., Li, N., and Sun, G. (2002) Application of Obturator to Treat Velopharyngeal 
Incompetence. Chinese Medical Journal, 115, 842-845.

[14] Sullivan, M., Gaebler, C., Beukelman, D., Mahanna, G., Marshall, J., Lydiatt, D., et al. (2002) Impact of Palatal Prosthodontic Intervention on Communication Performance of Patients Maxillectomy Defects: A Multilevel Outcome Study. Head \& Neck, 24, 530-538. https://doi.org/10.1002/hed.10095

[15] Yoshida, H., Michi, K. and Ohsawa, T. (1990) Prosthetic Treatment for Speech Disorder Due to Surgically Acquired Maxillary Defects. Journal of Oral Rehabilitation, 17, 565-571. https://doi.org/10.1111/j.1365-2842.1990.tb01427.x

[16] Aramany, M.A. (1978) Basic Principles of the Obturator Design for Partially Edentulous Patients. Part I: Classification. Journal of Prosthetic Dentistry, 40, 554-557. https://doi.org/10.1016/0022-3913(78)90092-6

[17] McAndrew, K.S., Rothenberger, S. and Minsley, G.E. (1998) An Innovative Investment Method for the Fabrication of a Closed Hollow Obturator Prosthesis. Journal of Prosthetic Dentistry, 80, 129-132. https://doi.org/10.1016/S0022-3913(98)70098-8

[18] Rieger, J.M., MDent, J.F.W., Jha, N. and Seikaly, H. (2003) Maxillary Obturators: The Relationship between Patient Satisfaction and Speech Outcome. Head \& Neck, 25, 895-903. https://doi.org/10.1002/hed.10299

[19] Toljanic, J.A. and Zucuskie, T.G. (1984) Use of a Palatal Reservoir in Denture Patients with Xerostomia. Journal of Prosthetic Dentistry, 52, 540-544. https://doi.org/10.1016/0022-3913(84)90342-1

[20] Kornblith, A.B., Zoltov, I.M., Gooen, J., Huryn, J.M., Lerner, T., Strpmg, E.W., et al. (1996) Quality of Life of Maxillectomy Patients Using an Obturator Prosthesis. Head \& Neck, 18, 323-334. https://doi.org/10.1002/(SICI)1097-0347(199607/08)18:4<323::AID-HED3>3.0.CO; 2-\#

[21] Sullivan, M., Gaebler, C., Beukelman, D., Mahanna, G., Marshall, J., Lydiatt, D., et al. (2002) Impact of Palatal Prosthodontic Intervention on Communication Performance of Patients Maxillectomy Defects: A Multilevel Outcome Study. Head \& Neck, 24, 530-538. https://doi.org/10.1002/hed.10095

[22] Rieger, J., Wolfaardt, J., Seikaly, H. and Jha, N. (2002) Speech Outcomes in Patients Rehabilitated with Maxillary Obturator Prostheses after Maxillectomy: A Prospective Study. The International Journal of Prosthodontics, 15, 139-144.

[23] Anderson, V.B. (2008) Static Palatography for Language Fieldwork. Language Documentation \& Conservation, 2, 1-27.

[24] Hardcastle, W.J., Gibbon, F.E. and Jones, W. (1991) Visual Display of TonguePalate Contact:Electropalatography in the Assessment and Remediation of Speech Disorders. British Journal of Disorders of Communication, 26, 41-74. https://doi.org/10.3109/13682829109011992

[25] Yamashita, Y., Michi, K.-I., Imai, S., Suzuki, N. and Yoshida, H. (1992) Electropalatographic Investigation of Abnormal Lingual-Palatal Contact Patterns in Cleft $\mathrm{Pa}$ late Patients. Clinical Linguistics \& Phonetics, 6, 201-217. https://doi.org/10.3109/02699209208985531 
Submit or recommend next manuscript to SCIRP and we will provide best service for you:

Accepting pre-submission inquiries through Email, Facebook, LinkedIn, Twitter, etc. A wide selection of journals (inclusive of 9 subjects, more than 200 journals)

Providing 24-hour high-quality service

User-friendly online submission system

Fair and swift peer-review system

Efficient typesetting and proofreading procedure

Display of the result of downloads and visits, as well as the number of cited articles Maximum dissemination of your research work

Submit your manuscript at: http://papersubmission.scirp.org/

Or contact jbm@scirp.org 